\title{
POSSIBLE COGNITIVE PROCESSES UNDERLYING COMPETENCY ASSESSMENT
}

\author{
R VAN WYK \\ $\mathrm{AB}$ BOSHOFF \\ Dept of Human Resource Management \\ University of Pretoria \\ CL BESTER \\ Dept of Industrial Psychology \\ University of the Orange Free State
}

\begin{abstract}
Indications are that research on competency assessment lacks a theoretical frame of reference. An attempt is made to explore cognitive processes taking place during assessment explaining the large percentage of rater variance. The principles of five different cognitive theories are discussed in the search for possible explanations namely: cognitive choice-, cognitive evaluation-, social cognitive theories, metacognitive- and the new paradigm approaches.
\end{abstract}

\section{OPSOMMING}

Aanduidings uit die literatuur is dat navorsing aangaande bevoegdheidsevaluering gebrekkig is aan ' $n$ teoretiese ondertoon. Ondersoek word ingestel na die kognitiewe prosesse wat plaasvind gedurende beoordeling wat aanduidend kan wees van die hoë persentasie variansie tussen evalueerders. Die beginsels van vyf verskillende kognitiewe teorieë word bespreek om moontlike verklarings te ondersoek, naamlik kognitiewe keuse-, kognitiewe evaluering-, sosiaal kognitieweteorieë, meta-kognitiewe- en die nuwe paradigma-benaderings.

Competency assessment is intended to align the objectives of an individual with that of the organisation, to optimise the level of performance of the individual and heighten his/her self-esteem. The aim of competency assessment is ultimately to maximise and maintain performance right through organisations by maintaining controls to produce the functioning of a productive unity. Three broad guidelines are identified as influencing competency assessment namely, actual job performance of evaluee, different biases of evaluators' perceptions and performance recall, and measurement error (Wherry \& Bartlett, 1982). This article is concerned with the possible cognitive processes taking place in work decisions, possibly related to biased perceptions of evaluators.

Ideally ratings should reflect an individual's actual performance. Research findings imply that this is not the case. Warr and Bourne (1999) indicate in two $360^{\circ}$ study samples, the congruence between ratings of different people and the discrepancy between these ratings were statistically independent. Ratings therefore seem to be subjective rather than objective. Theron and Roodt (1999) report similar findings. A statistical significant difference is reported between the performance ratings of managers vs. self-, customer- and peerratings, $(\mathrm{N}=68)$ indicating more conservative ratings by managers. Further analyses by these authors (Theron \& Roodt, 2000 ) indicate that $360^{\circ}$ rater groups have fairly unique views on different dimensions of competencies. In a study by Scullen, Mount and Goff $(2000)$, on average general job performance accounted for $13 \%$, dimensional performance for $8 \%$ and random error for $11 \%$ of the observed variance in competency assessment. Contrary to this, the idiosyncratic rater variance accounted for between $53 \%$ and $62 \%$ of the variance in competency assessment. Seeing that idiosyncratic ratings accounts for more than half of the variance, this presents a major challenge into the investigation of cognitive processes taking place during competency assessment ratings.

Keeping and Levy (2000) indicate that the research literature on competency assessment is in need of a theoretic framework to understand systematic differences of typical judgement patterns. Even with the marked increase of different $360^{\circ}$ performance rating techniques, there is limited research into

Requests for copies should be addressed to: $R$ van $W y k$, Department of Human

Resource Management, University of Pretoria, Pretoria, 0002 the judgement process (Warr \& Bourne, 1999). Different possible relationships could play a role in idiosyncratic variance, for instance between superior and sub-ordinate, subordinate and peer and self-ratings (see Theron \& Roodt, 1999, 2000). Rater biases can develop as systematic variance in competency assessment that has nothing to do with the actual performance of the sub-ordinate, but rather associated with bias of the rater. This could be due to attributive observations, affective/emotional responses, expectancies and motivations. This could in turn influence rater bias of halo error or leniency error (Theron \& Roodt, 1999, 2000).

Eventually rater bias could contribute to the motivation, performance and goal setting of the ratee. The inter-relationship between possible constructs playing a role in the variability in performance assessment is illustrated in figure 1.

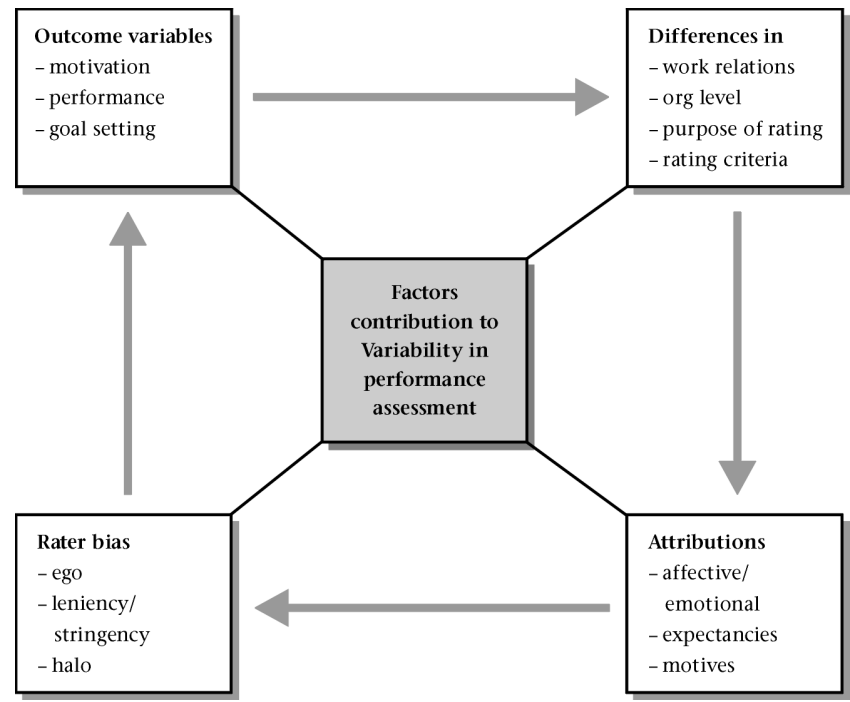

Figure 1: The inter-relationship between possible constructs playing a role in the variability in performance assessment

In this paper factors playing a role in idiosyncratic performance and consequent rater variance is investigated from a cognitive perspective. 


\section{Cognitive Theory}

Cognitive theory is defined as a group of theories that explain the learning process within the organism, such as cognitive schemes or expectancies formed or altered during the learning process (Plug, Meyer, Louw \& Gouws, 1986). The person generally recognised as the pioneer cognitive theorist is Edward Tolman (Luthans, 1998). He explains cognitive learning as relationships between cognitive environmental cues on the one hand and expectations on the other hand. This relationship theory was tested through controlled experimentation by proving that a rat could learn to find its way through an intricate maize, by making choices at cues, with search for food as goal.

Different cognitive theories and notions, as mainly classified by Kanfer (1990), are accordingly discussed in relation to competency assessment and the consequent relationship with rater variance, motivation, performance and goal setting. The cognitive theories of cognitive choice-, cognitive evaluation-, social cognitive-, meta-cognitive-theories, and the new paradigm approaches are discussed and illustrated in figure 2 .
Task engagement $=\Sigma[$ (motive to achieve success - motive to avoid failure) $\mathrm{x}$

$\Sigma$ ( $\Sigma$ of perceived success probabilities $\mathrm{x}$ value of success incentive of tasks)]

Raynor and Entin (1982) conducted a study to compare the number of attempts made to get the correct answer on maths problems under contingent and non-contingent situations. Contingent situations were identified as conditions where individuals were supposed to first find the correct solution to a maths problem before attempting the next more difficult problem, while in the non-contingent situation individuals were allowed to continue with more difficult problems even if previous solutions were not discovered. It was found that participants in the contingent situations made significantly more attempts to find the correct solution to problems than individuals in the non-contingent condition. In terms of the rationale of this theory the number of attempts increased in the contingency situation in order to maximise success, minimise failure, with the objective to increase the

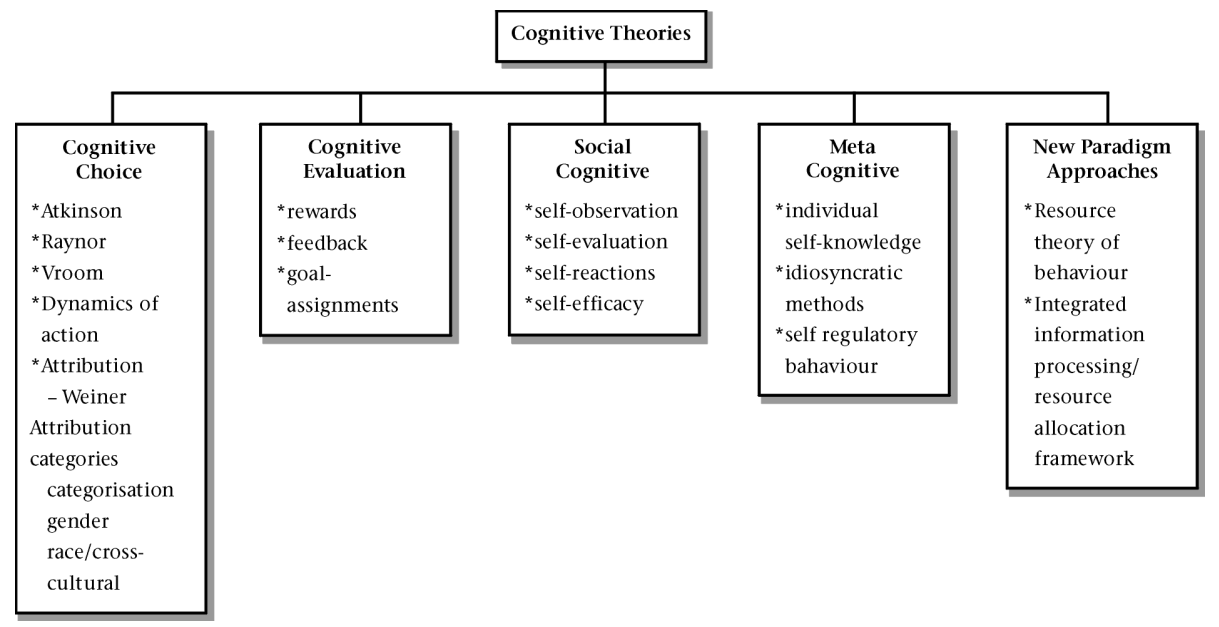

Figure 2: Cognitive theories

\section{Cognitive Choice Theories}

Cognitive choice theories are derived from the Expectancy $x$ Value $(\mathrm{E} \times \mathrm{V})$ theories focussing on two key constituents of subjective selection, namely expectations and evaluation of expected consequences (Kanfer, 1990). These E x V theories have in common that individuals make hedonistic choices in order to maximise positive affect and minimise negative affect. The $\mathrm{E} \mathrm{x}$ $\mathrm{V}$ models concentrate on decision behaviour rather than task or performance behaviour. Different Cognitive Choice Theories have since developed:

Atkinson's Theory of Achievement Motivation. Atkinson proposed the following formula for achievement motivation (Atkinson, 1957):

Task $=($ (motive to achieve success - motive to avoid failure $)$ $\Sigma$ perceived probability of task success $\mathrm{x}$ incentive value of task success).

This formula implies that individuals differ in how much their success motives and avoidance incentives weigh against one another. The argument follows that success oriented individuals perform and persist longer at tasks of intermediate difficulty and that failure-oriented individuals favour tasks that are at the extremes of either easy or difficult tasks.

Raynor's Theory of Future Orientation Effects and Achievement Motivation. This theory is an extension of the theory of Atkinson, in the sense that task performances are related to proceedings to following tasks (Raynor, 1969). The Raynor theory can be presented as: probability of total success. Applied to the work situation these findings could imply that individuals setting certain success standards before starting new tasks would maximise the quality of their work success.

Vroom's Valence-Instrumentality-Expectancy Theory. Vroom (1964) refers to valence as the individual's strength/value of preference for a particular event. Should a person have no preference for an outcome, the valence would be zero. If the person prefers not to have the outcome, the valence would be negative. Vroom's valence-instrumentalityexpectancy theory identifies persons' choices as influenced by perceptions with regard to three variables: (a) effortperformance expectancies (first-level outcome), (b) instrumentalities (relationships between performance and second-level outcomes of pay, praise or promotion) and (c) evaluation of valence (second-level outcome attractiveness). The function of instrumentality plays a major role in transforming first level outcomes to desired second level outcomes. The combination of perceived expectancies, instrumentalities and valences would serve as motivational forces in the work situation and lead to certain choices. In the competency assessment context it is hypothesised that when valences are anticipated to be high, motivational forces and effort levels are expected to be high. For instance, a sales representative may want to increase his/her income, realising that effort performance through elevated sales is the factor that leads to instrumentalities of increased pay and performance. The first level outcome is instrumental to obtaining the second level outcome of high sales and increased income. 
Attribution theory. The attribution theory refers to a set of theoretical principles explaining the way in which causal inferences are drawn of others' behaviour (Eiser, 1986). Eiser explains that attributions are methods of interpreting the behaviour or actions of others, categorising behaviour by making causal inferences. It is explained that an individual has a certain disposition of knowledge, in terms of which he/she attributes certain actions to an actor. Should behaviour deviate from previous or clearly defined roles, it would cry for explanation. This explains the phenomenon of the halo effect where raters expect employees to perform similar on different performance dimensions.

A further distinction is made between 'internal' and 'external' attributions. Actions or characteristics of an individual will be attributed as 'external', should the individual's action be seen as an out of the ordinary response for the specific individual to the situation. More consistent behaviours would more probably be attributed as 'internal', i.e. part of the individual's make-up. 'Internal' and 'external' behaviour is further evaluated in terms of perceived internal or external locus of control. Rotter (1966) explains that the general expectancies of individuals differ with regard to 'reinforcement of locus of control'. At the one extreme 'internally' oriented individuals ascribe reinforcements (feedback) received to personal attributes, at the other extreme 'externally' oriented individuals ascribe reinforcement (feedback) to chance or forces beyond their control. This could play a major role in egocentric bias.

Weiner's Attribution Theory. The attribution theory of Weiner is based on the literature on multidimensional scaling, factor-analysis and concept formation (Weiner, 1974). According to this theory three causal attributional dimensions are used in performance feedback and compensation, namely (1) locus of causality (internal/external), (2) the stability of outcomes (endurance across time and situations) and (3) perceived controllability (desired control). The hypothesis follows that perceived stability of outcome attributes strengthens outcome certainty.

In a study conducted by Staw (1975) based on attributions, individuals randomly assigned to two groups were separately informed that they either fell in a high performance group or a low performance group. Results showed that individuals randomly assigned to the high performance group saw their team mates as significantly more cohesive, superior in quality and quantity of communication and in total influence than the group identified as a low performance group. Further analysis indicated the high performance group enjoyed the task assignment significantly more, saw team mates as more interested in performing well, rated the ability of team mates and clarity of instructions higher than the members of the low performance group did. Attributions as self-fulfilling prophecies seem to play an important role in the dynamics of beliefs in performance.

\section{General Attribution Categories}

Categorisation. Feldman (1981) refers to the categorisation process taking place during competency assessment as an information organisation and storage course of action. The notion of automatic or controlled categorisation is explained in terms of perception, organisation and storage of information and stimuli that consistently fit into a category, enabling individuals to process large amounts of information. These categories form along the lines of informal correlations explaining the rater bias. The job of a nurse is for instance associated with working different shifts, hard physical work with the expectancy of social and professional skill. Recall of information would be channelled along the lines of general characteristics of a category, especially when specific information is not available, assumptions might be made on grounds of the prototype potentially leading to the halo effect or biased recall. Individual differences on grounds of the selection on categories may vary and affect and situational factors may determine the salience of a category. Should an individual deviate from the category or prototype, a problem-solving recategorisation process has to take place and attribution theory comes into action. The categorisation process can limit the selecting process during competency assessment. For instance a person that has to be evaluated in more than one category by one evaluator can easily evaluate the individual on grounds of a negative prototype formed of an individual in the previous situation, notwithstanding the contrary in the following situation, implicating biased recall. In a study by Smither, Buda and Reilly (1988) the effect of knowledge of a ratee's prior performance on present performance evaluation was examined. Rater subjects viewing extremely good and poor previous performance on videotape and in writing, viewed follow up 'average' performance as more extreme, than rater subjects who reviewed less extreme prior performances explaining biased recall.

Gender evaluation. Different studies on gender bias have showed no difference in the evaluation of males and females, eg. London and Stumpf (1983) Taylor and Falcone (1982) and Robbins and DeNisi (1993). Some studies investigating the evaluating both genders, indicate a favourable bias towards female subjects (Peters, O'Connor \& Wexley, 1984; Pulakos \& Wexley, 1983). In a summary by Landy and Farr (1980), research findings of the majority of the studies report no consistent effect of rater gender on ratings in laboratory and simulated settings. The study by Dobbins, Truxillo and Cardy (1988) indicate that female ratees were assessed less accurate by raters identified with traditional stereotypes of women, than raters identified having non-traditional stereotypes of women.

Robbins and DeNisi (1993) examined the cognitive characteristics in competency assessment, related to gender bias, in the light of the general lower job status and lower compensation of female workers. Results indicate that gender bias does not present as an influencing factor during rater appraisals of apprasees in gender congruent and incongruent occupations. These authors argue that the sensitisation of gender rights, gender discrimination and gender bias issues may currently play a role in the evaluation of raters. It may also be influenced by the motivational objectives to evaluate impartially, especially in gender incongruent jobs. Saal and Moore (1993) investigated the fairness of promotion decisions in fictitious court cases in a sample of 336 undergraduate students. Results indicated that both genders assessed promotion of the opposite gender as significantly less fair than that of their own gender.

The findings of the above studies seem to indicate that the effect of gender on raters' evaluation is inconclusive.

Race. Landy and Farr (1980) report a general finding of four studies that supervisors tend to give more positive ratings to subordinates of their own race, than to subordinates of another race.

Cross-cultural evaluation. According to Kovach (1999) the study conducted by him, is the first and as far as could be established the only empirically examining perceptions of appraisal between two nationalities. In this study it was found that Hungarians evaluated individual performance measures as less applicable and supportive of performance improvement than their American counterparts. Hungarians preferred the traditional appraisal by manager as more favourably, than American subjects who have a preference for self-appraisal.

The Dynamics of Action Approach. This approach, developed by Atkinson and Birch (1974), tries to explain and predict the continuation of stable behaviour and occurrence 
of change through historical development. The assumption of this approach is that multiple motivational tendencies operate continuously in individuals and that the behaviour of a person at a particular moment will be reflected in the strongest motivational tendency at the time, called consummatory forces. Consummatory forces can be overtaken by instigating forces when the culmination of motivation purposes overtakes the motivation of a previous activity. This leads to changes occurring in dominant motivational tendencies, as reflected by the coming and going of different directions of behaviour. It explains how a manager can switch from one enjoyable activity of engaging with top performing personnel to an activity with lower valence, such as goal-setting with low performing individuals. The directions of behaviour can again be influenced by inhibitory forces or forces of resistance. Activities could, for instance, be avoided when associated with former negative experiences. Research by Blankenship (1982) supports the consummatory view of Atkinson and Birch, where the consummatory influence proved to be greater for easy tasks than for difficult tasks in the low achievement group but the opposite for the high achievement orientated group. This could be an indication that high achievers search for higher more difficult challenges.

\section{Cognitive Evaluation Theory}

According to Kanfer (1990) the cognitive evaluation theory is part of the intrinsic motivation theories. The cognitive evaluation theory sees behaviour as being performed for its own sake, in the absence of perceivable extrinsic rewards. Different studies emphasise the harmful effects of external rewards on the continuance of task performance (Deci, 1971, 1972; Lepper, Greene \& Nisbett, 1973). In these studies the inhibiting influence of external rewards on persisting performance and subsequent internal motivation was evaluated by self-reports on tasks. When extrinsic rewards were present less time was spent on task execution during a period of free-choice than when extrinsic rewards were absent. It therefore seems that extrinsic rewards have an undermining effect on task interest and free-choice behaviour. It is further affirmed that intrinsic motivation has a continual influence on the person to do the task for satisfaction in itself. Rewards however have an optimal level of enhancing motivation, both too little and too large awards would be demotivating and lead to external motivation (McCormick \& Illgen, 1985). An optimal level of rewards being not too small or to large would lead to internal motivation. Organisations should be sensitised to the influence of rewards on employees' performance motivation.

Rewards. Performance contingent rewards are conceptualised as containing three elements, that is, evaluation, performance feedback and the value of the reward (Harackiewicz, Manderlink, \& Sansone, 1984). Harackiewicz, et al. (1984) explain that internal motivation on task interest is enhanced when evaluation is combined with rewards symbolising competency. On the other hand Weiner (1976) reports that extrinsic rewards can inhibit intrinsic motivation, when over compensation through extrinsic rewards take place. As these studies are done in laboratory settings, it is not clear what the influence would be in a field setting. The emphasis of the Harackiewicz, et al. study is however on rewards that symbolise achievement. It seems that the appropriateness of rewards in the work setting would be detrimental to intrinsic/extrinsic performance motivation.

Feedback. Different kinds of feedback are sought and received by individuals in organisations, to enable the individual to evaluate his/her personal competencies. Some studies indicate that feedback leads to intrinsic interest and task persistence, while others show no effect or a negative effect (Kanfer, 1990). It is argued that the reason for this inconsistent finding could lie in the differences in the amount of sufficient information accepted as acceptably assessing personal competence.

In an action research study by Meyer, Kay and French (1965) it is reported that criticism influences goal achievement in a negative manner, while praise has no effect. It is also indicated that defensiveness develops from critical negative appraisal procedures, leading to inferior performance. It is suggested that interviews to improve performance should be done separately from interviews relating to salary increases or promotion.

Feedback, enabling a judgement of competency (especially relative to others) was found to have a more positive influence on task enjoyment than no feedback at all (Sansone, 1986). This experiment was extended further and in a follow-up used ego-involvement in the feedback, by informing subjects that intellectual abilities were associated with task performance. Perceptions of high competence were, as predicted, significantly associated with task enjoyment. On the other hand, when competence was not made salient, enjoyment was determined more by individual differences than perceptions of competence.

Research by Harackiewicz and Larson (1986) on supervisor feedback styles, indicates that subordinate competence perceptions were highest when supervisors gave positive information on competence.

In a study by Benedict and Levine (1988) it was found that amongst subjects with at least 6 months of supervisory experience, female raters tended to delay feedback on competency assessment longer and positively distorted ratings significantly more than their male counterparts.

Goal assignments. Locke, Shaw, Saari \& Latham (1981) identify the goal setting notion as falling into the domain of cognitive psychology and cognitive behaviour modification, but also sees it as an important part of social learning. A goal is identified as a purpose or intent, a performance standard, objective or a deadline. It is an objective to attain a standard of proficiency by recognising task difficulty (specific task to be accomplished) and goal difficulty (aim of the goal).

Action research by Meyer, Kay and French (1965) indicates that mutual goal setting between superior and sub-ordinate advance performance. Intrinsic motivation on routine tasks also improved with goal assignments (Bryan \& Locke, 1967). Weiner (1976) found that tasks goals with a moderate subjective anticipation towards success lead to moderate affective intrinsic motivation. Task difficulty seems to be another possible moderator in the relationship of intrinsic motivation with goal setting.

In a summary by Locke, et.al (1981) of 48 different studies, full or partial support was found that difficult goals lead to higher performance than medium and easy goals, while only 9 studies failed to support it. These authors acknowledge individual differences caused by demographic variables, such as education, race, job tenure, age, and gender. Individual differences due to personality variables, such as need for achievement, need for independence, higher order strength, self-esteem and perception of locus of control are also acknowledged. Results concerning individual differences were however very inconsistent.

Evaluation of the goal assignment cognitive evaluation theory confirms the assumption of proximal goal assignments as leading more to intrinsic motivation than distal goal assignments (Bandura \& Schunk, 1981; Manderling \&Harackiewicz, 1984). Manderling and Harackiewicz (1984), however, found that the relationship is more complex and that intrinsic motivation declines when competence develops and therefore proximal goal assignments become more noticeable, 
giving it an external control character. These authors also consider skill, affect and the transparency of controlling properties of rewards and goals as mediating factors influencing intrinsic motivation as outcome. The main factor seems to be the development of competence with proximal goal assignments, which could possibly be transferred to distal goal assignments as competency increases.

Kanfer (1990) summarises the goal assignment studies by differentiating between proximal versus distal goal assignments as method of feedback on task performance. Proximal goal assignment involves a daily attainment of a goal, for instance by instructing a secretary to type a certain number of reports per day (for instance 10) apart from the daily duties. Distal goal assignment at the same level of difficulty would be to instruct a secretary to, apart from other duties type, 50 reports per week. According to the principles of the cognitive evaluation theory proximal goal assignment should increase intrinsic motivation, due to the frequent evaluation of competence, but could inhibit intrinsic motivation if too much external control is experienced. The less controlling character of distal goal assignments does not provide the frequent competence information stimulating internal motivation, but is experienced as less controlling and therefore less externally directed. According to the cognitive evaluation theory proximal goal assignment should, therefore, enhance more intrinsic motivation than distal goal assignment.

\section{Social Cognitive Theories}

The social cognitive theorists emphasise the influence of the interactive nature of cognition, social learning and environment on behaviour. Kanfer (1990) differentiates the social cognitive theory of Bandura from goal-setting, where goal-setting research focuses on the effects of goal attributes on skilled performance level, the cognitive social perspective concentrates on the cognitive processes underlying selfmotivation in acquiring skills and components and outcomes involved in self-regulation. Kanfer (1970) distinguishes between three major components of self-regulation in social cognitive theories, namely self-observation (selfmonitoring), self-evaluation (self-judgements), and selfreaction. A fourth component, is added by Bandura (1977), namely self-efficacy expectations.

Self-observation (self-monitoring). Self-monitoring refers to the selective attention of individuals to particular aspects of their behaviour. The selection of attention will be directed to activities of significance for the envisaged behavioural outcomes. Incentives for quality performance in organisations would, for instance, prompt individuals to seek methods to increase the quality of their products. Selfmonitoring enables individuals to gain knowledge of their task performance and the consequences thereof. This can be obtained from different sources, for instance, through feedback by external observers. Bandura and Cervone (1983) indicate that competency motivation can only be optimised when goal setting is combined with positive competency feedback. In a laboratory setting where subjects were subjected to three different interventions of (a) goal assignments, (b) competency feedback (c) goal assignments and competency feedback, a significantly higher level of effort was found in the group assigned to both goal and competency feedback.

Self-evaluation (self-judgements/self-appraisal). Selfevaluation takes place during competency and behaviour feedback. Individuals compare their competency feedback with their desired goal. In this comparison two kinds of affective reaction take place, namely self-reactions of satisfaction or dissatisfaction and expectations of selfefficacy (Kanfer, 1990).
Indications are that self-evaluation of the rater has an influence on the appraisal of the ratee. Mandell (1956) reports raters with low self-confidence being less lenient in ratings of others than raters high in self-confidence. This phenomenon is an indication of rater stringency bias. Parker, Taylor, Barrett \& Martens (1959) as well as Miller and Cardy (2000) report self-ratings to be inflated relative to real performance during self-appraisal. These findings refer to egocentric bias.

Self-reactions. Internal, typically affective responses take place during self-reactions. Dissatisfaction would be likely to follow self-evaluation of performance that is below one's goal and satisfaction if goals are met or exceeded (Kanfer, 1990). The discrepancy between the goals and evaluated performance will indicate the intensity and direction of the reaction. Major negative reactions could lead to the abandonment of goals, a decrease in interest and uncertainty about one's competence.

Pearce and Porter (1986) found a significant drop in organisational commitment over a 30-month period of employees who had been rated as "satisfactory" while employees who received higher ratings showed no change in commitment to the organisation. On the other hand Durecki (1997) reports no relationship between job satisfaction and job appraisals/competency outcomes in a study of teachers. The job satisfaction of teachers were rather influenced by the attitudes of the ratee towards perceptions of the rater, where the rater was ideally seen as a source of instructional improvement, giving unbiased responses.

Johnson and Ferstl (1999) investigated how self-ratings changed after feedback from sub-ordinates and found that managers who over-rated themselves relative to the ratings of others, improved their performance after 1 year and underraters' performance tended to decline. In the same study self-ratings of overraters tended to decrease and those of underraters increased.

Self-efficacy Expectations. Bandura (1977) added the selfefficacy expectation component to the self-regulation model. He describes this as individuals' self-perceived abilities to acquire specific tasks or goals. Bandura explains self-efficacy expectations as developed from different task-specific sources, such as competency assessment, social influences or previous performance accounts. Self-efficacy is differentiated from general affective responses to tasks, for instance, with an improved level of task performance, an individual's self-efficacy, that is, his/her belief in potential success may improve. The individual may, however, still maintain dissatisfaction with the task. A further distinction is drawn between self-efficacy expectations of capabilities of task performance and the expectancies of the $\mathrm{E} \mathrm{x} \mathrm{V}$ theories that refer to expected outcomes of tasks.

\section{Metacognitive Approaches}

Metacognitive approaches focus on individual differences in the accumulation of cognitive self-processes in learning behaviour (Kanfer, 1990). Through this approach an attempt is made to interpret the way in which individuals collect knowledge in goal-directed learning environments by using self-cognition and awareness to direct their own behaviour. It is therefore not a theory, but an approach that integrates different theoretic orientations and research findings to investigate individual orientations in self-regulation.

Brown (1987) differentiates between two forms of knowledge in the meta-cognitive domain namely: (a) self-knowledge of cognitive abilities; and (b) executive cognitive process through which cognitive activities are regulated during task performance and learning processes. Knowledge in the meta-cognitive domain is therefore a combination of an individual's self- 
knowledge, with idiosyncratic methods of self-regulatory behaviour due to motivation, directed attention and the organisation of knowledge.

\section{The New Paradigm Approaches}

Kanfer (1990) explains that in the new paradigm approaches, researchers use diverse constructs and theories from different fields of psychology to explain phenomena in organisational behaviour. The emphasis is here to initially explain behaviour and eventually to predict it.

The resource theory of behaviour in organisations. This theory by Naylor, Pritchard and Ilgen (1980) has the status of a cognitive choice theory. This is a comprehensive theory, integrating various theories of conceptualisation of action and decision-making. This theory forms a bridge between the $\mathrm{E} \times \mathrm{V}$ theory and the Atkinson and Birch dynamics of action theory, by explaining an individual's information processing as evolving from perceptions of various contingencies, leading to choices derived from bivariate functions of these contingencies. For instance, if the function between effort and performance is perceived as positive, the belief could evolve that performance will increase with the increase in effort, but with a diminishing in returns as an asymptote is reached.

The Naylor, et al. (1980) theory further integrates some of the $\mathrm{E}$ $\mathrm{x} \mathrm{V}$ theories with two additional features, (a) individuals are seen as distributing their time and effort in anticipation of maximum positive affect, influencing motivation, (b) motivation is seen as a resource allocation phenomenon, as task commitment can, for example, be seen as the product of commitment to task relevant and task irrelevant actions. This process reveals the proportion of willingness of an individual to devote personal resources to a target task.

This theory also explains the cognitive actions involved in contingencies of outcome-evaluation and evaluation-reward contingencies. Effort of task performance will be evaluated in relation to organisational outcome assessment and reward procedures, which will eventually influence choice behaviour by the individual employee.

The integrated information processing/resource allocation framework. This approach developed by Kanfer (1990) is an attempt at developing an integrated framework of theories of human information processing that connects ability, motivation and task characteristics. It departs from the Naylor, Pritchard and Ilgen (1980) frame of reference in three ways: (a) individual differences in the availability of cognitive resources are investigated against the background of the influence of cognitive resource demands, (b) selfregulating phenomena are investigated with the distinction between the allocation of distal and proximal resources as frame of reference, and (c) the resource capacity of the individual is seen as a function of his/her level of cognitive ability. This framework integrates different theories of human information processing concerning ability, motivation and task characteristics.

According to the characteristics of the integrated information processing/resource allocation framework tasks are either seen as resource dependent or resource incentive. It is the product of the relationship between cognitive resource devotion and outcome task performance level. Tasks that are resourcedependent are evaluated according to the product of the outcome between cognitive/attention resources accompanied by changes in performance. A secretary could for instance advance her typing skills by improving speed and accuracy. On the other hand, tasks that are resource-incentive have limited performance potential. Due to the character of the task, changes in attentiveness has hardly any influence on performance, for example administrative work. This kind of analysis, based on perceived performance-resource information, involves the three cognitive mechanisms of performance-utility function, effort-utility function, and perceived effort-performance utility relation.

The information processing is in the case of this theory similar to the $\mathrm{E} x \mathrm{~V}$ models of attention allocation: perceived performanceand effort-utility functions are maximised through perceived effort-performance resource functions. The performance-utility function refers to perceptions of attractiveness of differentiated performance levels in relation to internal and external outcomes. The effort-utility function refers to the amount of effort perceived by the individual, so that tasks that are either too simple or too difficult, requiring too little or too much effort, are both seen as unattractive. The perceived effort-performance function, is the critical co-ordination of the perceived performance- and effortutility functions as translated into personal interpretations and attributions of effort. This model provides an approach to the evaluation of the product of perceived performance level as associated with external and external outcomes, task complexity and effort-utility on goal performance.

\section{DISCUSSION}

The cognitive approach provides management with a framework of a variety of instruments to determine relationships and predictions. It enables management to evaluate the reciprocal influence between competency assessments on cognitive processes, affecting future performance. It therefore serves as a link between theory and practice that gives insight into longterm job performance.

Different appraisals should be conducted for divergent purposes, as it is unrealistic to expect one form of appraisal to answer to all the assessment needs. On the other hand, when more than one appraisal is done, one should be cautious of bias due to previous evaluations. It is important that criticism should be avoided. Raters should not only be trained to use evaluation instruments, but should also be sensitised to possible cognitive processes that may influence attributions leading to rater bias.

Feldman (1981) suggests that an organisation should see to it that valid evaluations have positive consequences for both evaluator and evaluee. This author suggests that the cognitive and psychometric research on competency assessment should continue, but with some modifications. Modification should include better formulated psychometric instruments to prevent response biases, halo effects or leniency/stringency.

Locke, et al. (1981) see the findings with regard to the effects of goal setting as one of the most beneficial, robust and replicable findings in the psychological literature. The authors indicate that goal setting is most likely to influence performance in terms of type of goals (easy/difficult), goal specificity, ability of individuals, knowledge of performance evaluation, as well as participation by the organisation by being supportive and acknowledging individual differences. Goal setting should involve both parties namely superior and sub-ordinate. Goal setting on a proximate basis is seen as less threatening to the individual than a yearly appraisal. Inconsistencies concerning individual differences in especially goal setting, needs further investigation through research, such as the influence of rewards, competition and high pressure.

Feldman (1981) criticises the attribution process of competency assessment. While acknowledging it as relevant, due to its stimulus-based judgements, he argues that it does not take into account the cognitive selection and storage of information processes necessary to make memory based judgements. 
Robbins and DeNisi (1993) emphasise the inaccuracy of the cognitive approach, as a result of the limitations of human nature in the processing of information. Kanfer (1990) indicate that the $\mathrm{E} \times \mathrm{V}$ models are seen to have limited theoretical and practical usefulness due to the situational and individual character of the theories and therefore weak generalisability.

Fraser and Zarkada-Fraser (2001) indicate that task based $360^{\circ}$ evaluations should be performed rather than competency based evaluations, leading to higher degrees of anonymity. On the other hand, cognitive processes must acknowledge the upper limit of validity admitting the lack of total freedom of bias and absolute accuracy, seeing that the reliability of even the best trained observer is subjected to mood.

Many of the research done on the cognitive processes involved in competency assessment are laboratory studies, with little generalisation possibilities. It is suggested that cognitive research should not only concentrate on realistically portraying appraisal situations in laboratory environments but the testing of relevant variables should be duplicated in field settings to improve generalisability.

Intercultural cognitive processes in competency assessment ratings seems to be an under developed research field. This is however an important concept to accommodate with the increase of globalisation.

The new paradigm approaches are very complex to test in its totality. It is suggested that these approaches are used to explain specific phenomena. Cognitive theory enables the researcher to investigate cognitive schemata that take place within the organism during competency assessment. It allows the investigation of possible relationships as well as predictions of behaviour with competency assessment.

The pure cognitive theory in itself has its limitations to explain cognitive processes taking place during or due to evaluation. Therefore the development of cognitive approaches acknowledging other theories and paradigms, such as the social cognitive theories and meta-cognitive and new paradigm approaches. On the other hand the development of paradigms trying to explain the integration of many variables, are difficult to measure.

Not withstanding the weaknesses, the implementation of cognitive theory in the investigation of cognitive processes taking place in relation to competency assessment has made a large contribution to the knowledge of competency assessment in organisational behaviour and the improvement of performance.

\section{REFERENCES}

Atkinson, J.W. (1957). Motivational determinants of risk-taking behavior. Psychological Review, 64, 359-372.

Atkinson, J.W., \& Birch, D. (1974). The dynamics of achievementoriented activity. In Atkinson, J.W. \& Raynor, J.O. (Eds.), Motivation and Achievement. Washington, DC: Winston \& Sons.

Bandura, A. (1977). Self-efficacy: Toward a unifying theory of behavioral change. Psychological Review, 84, 191-215.

Bandura, A., \& Cervone, D. (1993). Self-evaluative and selfefficacy mechanisms governing the motivational effects of goal systems. Journal of Personality and Social Psychology, 45, 1017-1028.

Bandura, A., \& Schunk, D. (1981). Cultivating competence, selfefficacy, and intrinsic interest through proximal selfmotivation. Journal of Personality and Social Psychology, 41, 586-698.

Benedict, M.E., \& Levine, E.L. (1988, August). Delay and distortion: tactic influences on performance appraisal effectiveness. Journal of Applied Psychology, 73 (3), 507-515.
Blankenship, V. (1982). The relationship between consummatory value of success and achievement task difficulty. Journal of Personality and Social Psychology, 42, 901-914

Brown, A.L. (1987). Metacognition, executive control, selfregulation, and other more mysterious mechanisms. In F.E. Weinert \& R.H. Kluwe (Eds.), Metacognition, motivation, and understanding (pp. 65-116). Hillsdale, NJ: Erlbaum.

Deci, E.L. (1971). Effects of externally mediated rewards on intrinsic motivation. Journal of personality and Social Psychology, 18, 105-115.

Deci, E.L. (1972). Effects of contingent and non-contingent rewards on controls on intrinsic motivation. Organizational Behaviour and Human Performance, 22, 113-120.

Dobbins, G.H., Truxillo, D.M., \& Cardy, R.L. (1988, August). The effects of purpose of appraisal and individual differences in stereotypes of women on sex differences in performance ratings: a laboratory and field study. Journal of Applied Psychology, 73 (3), 551-559.

Dunnette, M.D. \& Hough, L.M. (Eds.). (1990). Handbook of Industrial and Organizational Psychology. Volume 1 ( $2^{\text {nd }}$ Ed). California: Consulting Psycholgists Press.

Eiser, J.R. (1986). Interpersonal attributions. In H. Tajfel, \& C. Fraser (Eds.). Introducing Social Psychology (pp. 235-255). Harmondsworth: Penguin Books.

Feldman, J.M. (1981). Beyond attribution theory: cognitive processes in performance appraisal. Journal of Applied Psychology, 66 (2), 127-148

Fraser, C. \& Zarkada-Fraser, A. (2001, March). Perceptual polarization of managerial performance from a human resource management perspective. International Journal of Human Resource Management. 12 (2), 256-269.

Harackeiewicz, J.M., \& Larson, J.R. (1986). Managing motivation: The impact of supervisor feedback on surbordinate task interest. Journal of Personality and Social Psycholgy, 51, 547-556.

Harackeiewicz, J.M., Sansone, C., \& Manderlink, G. (1985). Competence, achievement orientation, and intrinsic motivation: A process analysis. Journal of Personality and Social Psychology, 48, 493-508.

Johnson, J.W., Ferstl., K.L. (1999, Summer). The effects of interrater and self-other agreement on performance improvement following upward feedback. Personnel Psychology, 52 (2), 271-284.

Kanfer, F.H. (1970). Self-regulation: Research, issues and speculations. In C. Neuringer \& K.L. Michael (Eds.), Behavior Modification in Clinical Psychology. New York: AppletonCentury-Crofts.

Kanfer, R. (1990). Motivation theory and industrial and organizational psychology. In Dunnette, M.D. \& Hough, L.M. (Eds.), Handbook of Industrial and Organizational Psychology. Volume 1 (2nd Ed). (pp.75-170). California: Consulting Psycholgists Press.

Keeping, L.M. \& Levy, P.E. (2000). Performance appraisal reactions: measurement, modeling, and method bias. Journal of Applied Psychology, 85 (5), 708-723.

Landy, F.J. \& Farr, J.L. (1980). Performance rating. Psychological Bulletin, 87 (1), 72-107.

Locke, E.A., Shaw, K.N, Saari, L.M. \& Latham, G.P. (1981). Goal setting and task performance: 1969-1980. Psychological Bulletin, 90 (1), 125-152.

London, M. \& Stumph, S.A. (1983). Effects of candidate characteristics on management promotion decisions: An experimental study. Personnel Psychology, 36, 241-259.

Kovach, K. Jr. (1999, January). Attitudes toward performance and the performance evaluation process: issues of nationality, organizational size, and job level. Dissertation-AbstractsInternational: Section B: The Sciences and Engineering, 60 (6-B), 2998

Lepper, M.R., Greene, D. \& Nissbett, R.E. (1973). Undermining children's intrinsic interest with extrinsic rewards: A test of the "overjustification" hypothesis. Journal of Personality and Social Psychology, 28, 129-137. 
Luthans, F. (1998). Organizational Behavior (8 ${ }^{\text {th }}$ Ed). Boston: Irwin McGraw-Hill.

Mandell, M.M. (1956). Supervisory characteristics and ratings: a summary of recent research. Personnel Psychology, 32, $435-440$

Manderling, G., \& Harackiewicz, J.M. (1984). Proximal versus distal goal setting and intrinsic motivation. Journal of Personality and Social Psychology, 47, 918-928.

Mc Cormick, E.J. \& Illgen, D.R. (1985). Industrial and Organizational Psychology ( $8^{\text {th }}$ Ed.). London: Allen \& Unwin.

Meyer, H.H., Kay, E. \& French, J.R.P., Jr. (1965). Split roles in performance appraisal. Harvard Business Review, 43, 123-29.

Miller, J.S., \& Cardy, R.L. (2000, September). Self-monitoring and performance appraisal: rating outcomes in project teams. Journal of Organizational Behavior, 21 (6), 609-626.

Naylor, J.C., Pritchard, R.D., \& Ilgen, D.R. (1980). A theory of behavior in organizations. New York: Academic Press.

Parker, J.W., Taylor, E.K., Barrett, R.S., \& Martens, L. (1959). Rating scale content: III. Relationships between supervirory and self-ratings. Personnel Psychology, 12, 49-63.

Pearce, J.L., Porter, L.W. (1986, May). Employee responses to formal performance appraisal feedback. Journal of Applied Psychology, 71 (2), 221-219.

Peters, L.H., O'Connor, E.J. \& Wexley, J. (1984). Sex bias and managerial evaluations: A replication and extension. Journal of Applied Psychology, 69, 349-352.

Plug, C., Meyer, W.F., Louw, D.A. \& Gouws, L.A. (1986). Psigologie Woordeboek. Johannesburg: McGraw-Hill.

Pulakos, E.D. \& Wexley, K.N. (1983). The relationship among perceptual similarity, sex, and performance ratings in managersubordinate dyads. Academy of Management Journal, 26, 129-139.

Smither, J.W., Buda, R. \& Reilly, R.R. (1988). Effect of prior performance information on ratings of present performance: contrast versus assimilation revisited. Journal of Applied Psychology, 73 (3), 487-497.

Raynor, J.O. (1969). Future orientation and motivation of immediate activity: An elaboration of the theory of achievement motivation. Psychological Review, 76, 606-610.

Raynor, J.O., \& Entin, E.E. (1982). Achievement motivation as a determinant of persistence in contingent and noncontingent paths. In J.O. Raynor \& Entin (Eds), Motivation, career striving, and aging. (pp.83-92). Washington, DC: Hemisphere.
Robbins, T.L., \& De Nisi, A.S. (1993. Spring). Moderators of sex bias in the performance appraisal process: a cognitive analysis. Journal of Management. 19 (1), 113-127.

Saal, F.E., \& Moore, S.C. (1993, February). Perceptions of promotion fairness and promotion candidates' qualifications. Journal of Applied Psychology, 78 (1), 105-111.

Sansone, C. (1986). A question of competence: The effects of competence and task feedback on intrinsic interest. Journal of Personality and Social Psychology, 51, 918-931.

Scullen, S.E., Mount, M.K. \& Goff, M. (2000). Understanding the latent structure of job performance ratings. Journal of Applied Psychology, 85 (6), 956-970.

Singer, MG. (1990). Human Resource Management. Boston: PWS/KENT Publishing.

Smither, J.W., Buda, R., \& Reilly, R.R. (1998, August). Effect of prior performance information on ratings of present performance: contrast versus assimilation revisited. Journal of Applied Psychology, 73 (3), 487-587.

Staw, B.M. (1975). Attribution of the "causes" of performance: a general alternative interpretation of cross-sectional research on organizations. Organizational Behavior and Human Performance, 13, 414-432.

Theron, D. \& Roodt, G. (1999). Variability in multi-rater competency assessments. Journal of Industrial Psychology, 25 (2), 21-27.

Theron, D. \& Roodt, G. 2000. Mental models as moderating variable in $360^{\circ}$ competency assessments. Journal of Industrial Psychology, 26 (2), 14-19.

Taylor, S.E. \& Falcone, H. (1982). Cognitive bases of stereotyping: The relationship between categorization and prejudice. Personality and Social Psychology Bulletin, 8, 426-432.

Vroom, V.H. (1964). Work and motivation. New York: Wiley.

Warr, P \& Bourne, A. (1999). Factors influencing two types of congruence in multirater judgments. Human Performance, 12 (3/4), 183-211.

Weiner, B. (1974). An attributional interpretation of expectancyvalue theory. In Weiner B. (Ed.). Cognitive views of human motivation. (pp.51-69). New York: Academic Press.

Weiner, B. (1976). Motivation from the cognitive perspective. In Estes, W.K., (Ed.). Handbook of Learning and Cognitive Processes. Volume 3. Approaches to Human Learning and Motivation. (pp.283-307). New York: John Wiley.

Wherry, R.J., Sr., \& Bartlett, C.J. (1982). The control of bias in ratings: a theory of rating. Personnel Psychology, 35, 521-551. 